\title{
Homozygous cystinuria and the oculo-cerebro-renal dystrophy of Lowe in same family
}

\author{
R. R. BAILEY, R. W. CARRELL, and F. T. SHANNON \\ From the Department of Renal Medicine, Christchurch Hospital, and Departments of Paediatrics and Clinical \\ Biochemistry, Christchurch Clinical School, Christchurch, New Zealand
}

\begin{abstract}
Bailey, R. R., Carrell, R. W., and Shannon, F. T. (1976). Archives of Disease in Childhood, 51, 558. Homozygous cystinuria and the oculo-cerebro-renal dystrophy of Lowe in same family. The mother and daughter in a family had homozygous cystinuria and were also heterozygous carriers of the oculo-cerebro-renal dystrophy of Lowe. The daughter was also epileptic. The son had Lowe's syndrome and the father an increased urinary excretion of cystine and lysine. This evidence together with other case reports suggests that the defect in cystinuria and that of Lowe's syndrome may be connected.
\end{abstract}

The oculo-cerebral-renal dystrophy of Lowe and cystinuria are both rare hereditary disorders. One patient with the former syndrome has been reported in New Zealand (Johnson, 1966). His mother and sister carry the gene for Lowe's syndrome and also have cystinuria. His father excretes increased quantities of cystine and lysine in the urine.

This paper reports the details of this family. No history of consanguinity could be obtained.

\section{Family history}

Mother. A 35-year-old mother of two children was found by an ophthalmologist to have a visual acuity of $6 / 6$ in both eyes. She had a subcapsular posterior polar opacity in the right lens and in the left lens polychromatic lustre in the posterior pole with bubbles in the subcapsular cortex. When aged 37 and again a year later she had acute left pyelonephritis. After the second attack she was referred for renal assessment. Her blood pressure was $120 / 70 \mathrm{~mm} \mathrm{Hg}$, height $157.5 \mathrm{~cm}$, and weight $53 \mathrm{~kg}$. The lenticular opacities were again noted. The patient had two sisters, both of whom were reported to be well. Ophthalmological examination of one sister was normal. One sister has had three normal sons, the other sister three healthy daughters. The patient's father died at the age of 32 from pneumonia and her mother died at $\mathbf{5 2}$ from an unknown cause.

At the time of referral a voided morning urine specimen contained no protein, 20 white cells $/ \mathrm{mm}^{3}$, no red cells, numerous cystine crystals, cystine casts and was sterile on culture. An intravenous pyelogram showed a slightly radio-opaque staghorn calculus in the left kidney causing considerable obstructive dilatation.

Received 13 November 1975.
The sodium nitroprusside screening test for cystine was strongly positive and high voltage electrophoresis of the urine showed much increased bands of cystine, lysine, arginine, and ornithinine typical of cystinuria (Fig.). This was confirmed by analysis of urine on an automated amino acid analyser. The blood urea was $26 \mathrm{mg} / 100 \mathrm{ml}$, serum creatinine $0.7 \mathrm{mg} / 100 \mathrm{ml}$, mean 24-hour creatinine clearance $55 \mathrm{ml} / \mathrm{min}$, mean 24-hour protein excretion $90 \mathrm{mg}$, serum calcium $9.2 \mathrm{mg} / 100 \mathrm{ml}$, serum phosphorus $4.0 \mathrm{mg} / 100 \mathrm{ml}$, and the serum uric acid $4.6 \mathrm{mg} / 100 \mathrm{ml}$. After 5 units of intramuscular pitressin tannate in oil the patient concentrated her urine to $654 \mathrm{mOsm} / \mathrm{kg}$ water. A standard ammonium chloride test $(0.1 \mathrm{~g} / \mathrm{kg}$ orally) resulted in a minimum urine $\mathrm{pH}$ of $5 \cdot 3$.

A $5 \cdot 4 \mathrm{~g}$ staghorn calculus removed from the left kidney was composed of cystine with a trace of calcium oxalate. After the operation the creatinine clearance was 94 $\mathrm{ml} / \mathrm{min}$. Over the next five years she was lost to medical follow-up and failed to maintain the recommended high daily fluid intake of 41 .

At the age of 43 she developed acute left ventricular failure. Cardiological investigations showed her to have mild mitral stenosis, mitral incompetence, and aortic incompetence. The following year pain in the left loin recurred. Radiological investigations showed a non-functioning kidney due to obstruction at the pelviureteric junction by a partly opacified calculus. The blood urea was $43 \mathrm{mg} / 100 \mathrm{ml}$ and the serum creatinine $1.3 \mathrm{mg} / 100 \mathrm{ml}$. The urine was sterile but contained 130 white cells $/ \mathrm{mm}^{3}$. Nephrolithotomy was again undertaken. The renal pelvis and calyces were much dilated and contained a large quantity of pus and several cystine calculi. The patient is now following a high fluid intake regimen together with $3 \mathrm{~g}$ of sodium bicarbonate before retiring. 

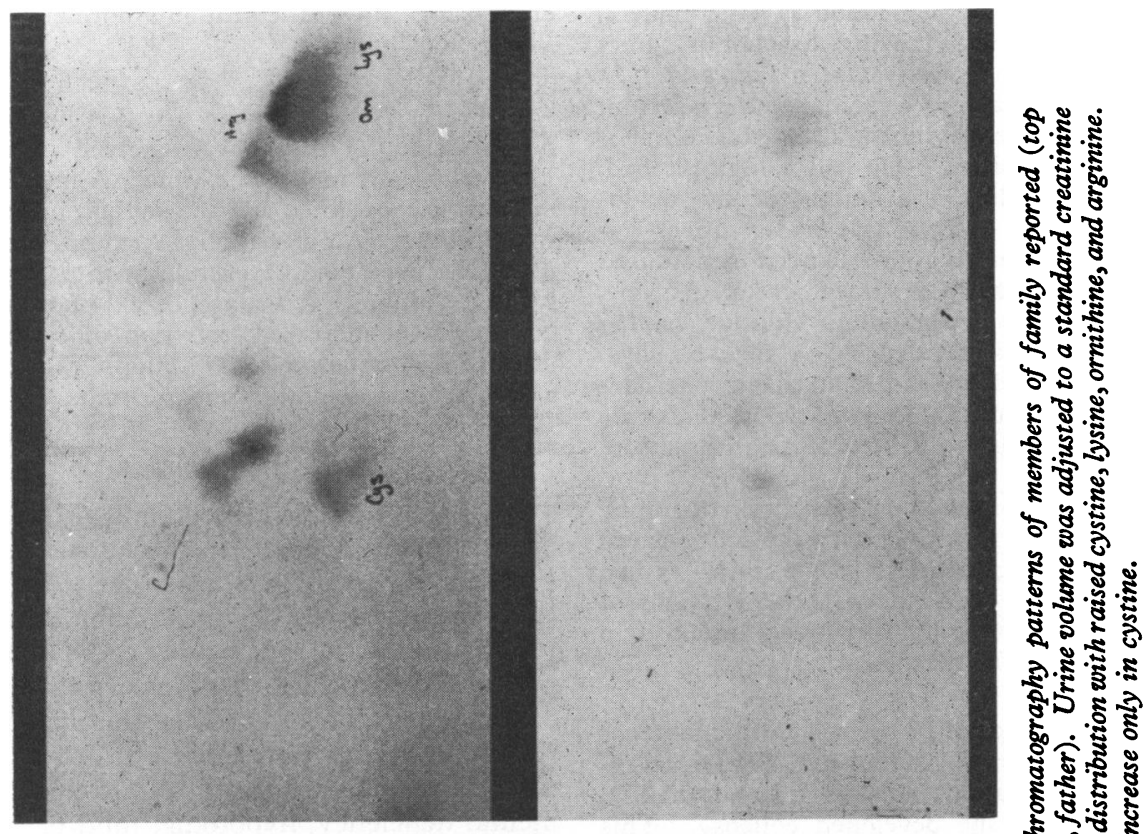

ร.).

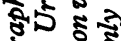

ธิ․ำ

छิ ฐ
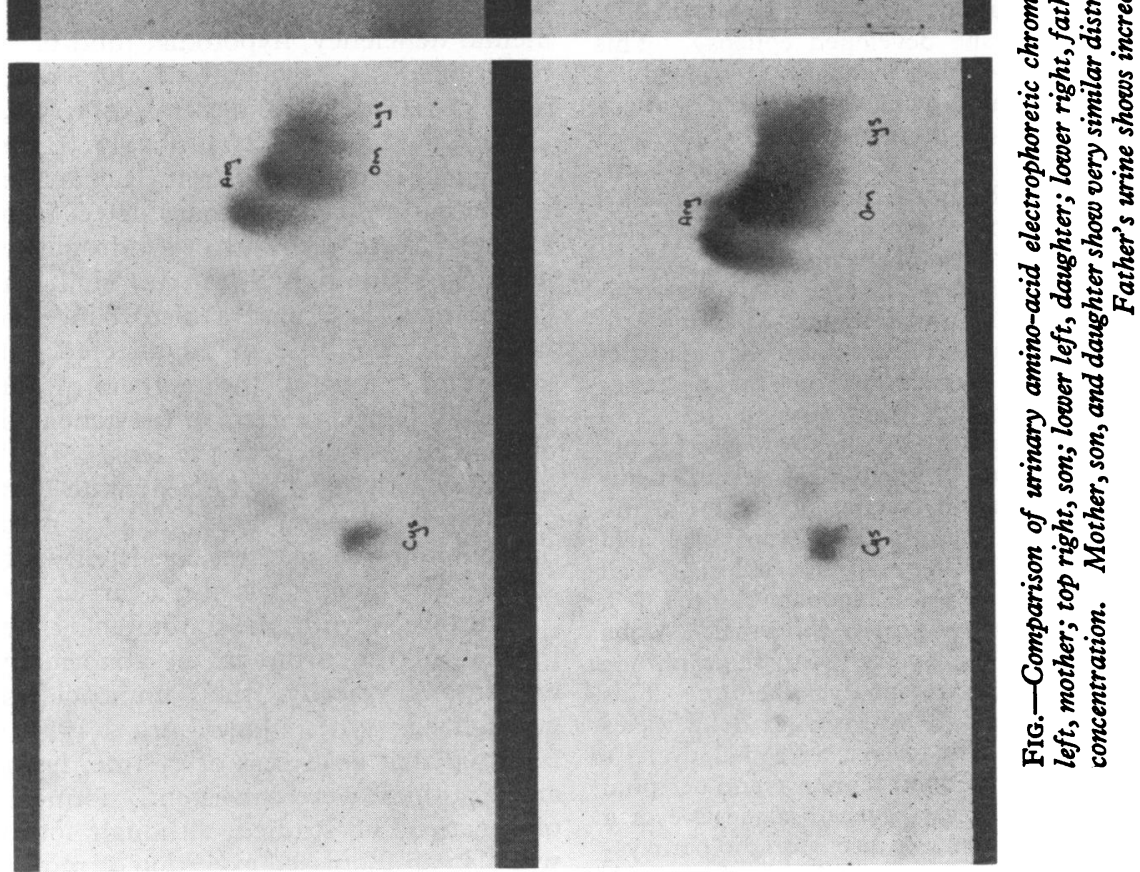
Son. At the age of 11 months this patient was admitted to hospital for investigation of failure to thrive and mental retardation. He was found to have bilateral congenital central cataracts, roving nystagmus, gross hypotonia, and areflexia. He was seen regularly. At the age of $3 \frac{1}{2}$ years he had more spontaneous movement and reasonable power in his limbs, although the hypotonia and areflexia persisted. He had a high-pitched, piercing scream. A clinical diagnosis of the oculocerebro-renal dystrophy of Lowe was made. Investigation showed him to have a pronounced generalized hyperaminoaciduria, which included cystine, lysine, arginine, and ornithine. Ammonium chloride loading (50 $\mathrm{mEq}$ daily in four divided doses for six days) resulted in a marked acidaemia but an inability to adequately acidify the urine. He was reported as the first case of Lowe's syndrome in New Zealand (Johnson, 1966).

At the age of 7 and again at 13 urinary chromatography showed the distribution of amino-acids typically seen in cystinuria-increased quantities of cystine, lysine, arginine, and ornithine with normal concentrations of the other amino acids (Fig.). Automated amino acid analysis confirmed this distribution.

Daughter. At the age of 17 months this patient was hospitalized with a febrile convulsion. Physical examination and investigations showed no abnormality. At the age of 3 years she developed epilepsy. This consisted of one to two minor attacks each week in which her right arm and hand flexed. Each attack lasted only a few seconds, during which she appeared dazed. At the age of 9 a random urine specimen contained cystine crystals and the sodium nitroprusside test was positive. High voltage electrophoresis of the urine showed much increased excretion of cystine, lysine, ornithine, and arginine (Fig.). This was confirmed by analysis of urine on an automated amino acid analyser. Her eyes showed a few subcapsular opacities at the posterior pole. Reflection from the posterior capsule was polychromatic. She was on the 25th centile for weight and the 10th centile for height for her age. The blood urea was $19 \mathrm{mg} / 100 \mathrm{ml}$, serum creatinine $0.8 \mathrm{mg} / 100 \mathrm{ml}$, serum calcium $9.4 \mathrm{mg} / 100 \mathrm{ml}$, serum phosphorus $3.8 \mathrm{mg} / \mathrm{ml}$, and serum uric acid $5.4 \mathrm{mg} / 100 \mathrm{ml}$. After an ammonium chloride load $(0 \cdot 1 \mathrm{~g} / \mathrm{kg})$ she acidified her urine adequately to $\mathrm{pH} 5 \cdot 3$. An electroencephalogram was grossly abnormal. Alpha rhythm was present at 8.5-9 cycles/s with an amplitude of up to $100 \mu \mathrm{V}$ in response to eye opening. This rhythm was often suppressed by irregular delta waves on the left. Irregular delta waves at 1.5-2 cycles/s were most pronounced in the left temporal and occipital areas and showed some phase reversal suggestive of a mid-temporal focus. There was also sporadic paroxysmal activity which was mainly right-sided, though showing some tendency to generalization at times in anterior areas. Typical paroxysms lasted about $1.5 \mathrm{~s}$ and consisted of 4 cycles/s waves of very high voltage with few irregular spikes.

At the age of 12 an intravenous pyelogram was normal.
At the age of 14 her epileptic attacks were being controlled with carbamazepine and phenytoin. An electroencephalogram was essentially normal. She was on a high fluid intake.

Father. At 39 years of age this healthy man with no past medical history was assessed as an outpatient. Physical examination was normal. A morning specimen of urine was obtained and the sodium nitroprusside test was positive. An electrophoretogram (Fig.) showed an increased excretion of cystine with marginally raised lysine. Amino acid analysis of a 24-hour urine sample confirmed an increased excretion of cystine and 1270 $\mu \mathrm{mol}$ of lysine (normal $<900 \mu \mathrm{mol}$ ). The other dibasic amino acids were within normal limits.

\section{Discussion}

In 1952 Lowe, Terrey, and MacLachlan described a clinical entity in three male infants which consisted of organic-aciduria, decreased production of renal ammonia, hydrophthalmos, and mental retardation. Abbassi, Lowe, and Calcagno (1968) reviewed 57 reported cases together with 13 of their own. They concluded that the syndrome was a rare congenital hereditary disorder limited to males and characterized by growth retardation, mental deficiency, hypotonia, mild or severe metabolic acidosis, generalized hyperaminoaciduria, proteinuria, rickets, bilateral cataracts, and glaucoma. The disease is probably transmitted as a sex-linked intermediate trait (Richards et al., 1965).

The nature of the primary defect from which the various features of the syndrome originate is unknown, although Schwartz, Hall, and Gabuzda (1964) have described a disturbance in the metabolism of ornithine in an affected patient. The important feature of the mothers of affected males and of all female carriers of the gene is the presence of punctate opacities in the lens. The boy in this family was thought to be a definite example of the syndrome (Johnson, 1966) and his mother has the ophthalmological features consistent with the carrier state. The daughter is also a carrier of the gene.

In Lowe's syndrome amino acids are constantly present in the urine in an abnormally increased amount. Typically, the aminoaciduria is of a generalized type. Jagenburg (1959), however, reported that an excess of cystine, lysine, arginine, and ornithine were consistently found in the urine of a patient he studied, although sometimes there was also an increased excretion of most of the other urinary amino acids. He concluded that the amino acid excretion in his patient partly tallied with that found in cystinurics. However, there was no family history of cystinuria. This unusual distribution of excess amino acids was seen in the 
patient reported in this paper when he was aged 7 and again when 13, although when he was aged 11 months he excreted increased amounts of 18 aminoacids, including the dibasic amino acids (Johnson, 1966). Terslev (1960) found that the mother of one of his patients with Lowe's syndrome had albuminuria and marked cystinuria. Although paper chromatography 'gave negative results' Terslev concluded that she had cystinuria.

Cystinuria is a relatively rare condition in which renal tubular reabsorption of cystine, lysine, arginine, and ornithine as well as homocysteinecysteine disulphide (Frimpter, 1961) and homoarginine (Cox and Cameron, 1974) is defective. The transport defect in the kidney is associated with a corresponding defect in the gastrontestinal tract. The transmission of cystinuria is autosomal recessive in pattern but there is some heterogeneity. The incidence of the homozygous abnormality is about one per 20000 of the population (Crawhall and Watts, 1968). The incidence in New Zealand is not known. However, in a New Zealand study cystinuria was responsible for $0.7 \%$ of renal stones in men and $4.0 \%$ of stones in women (Bailey et al., 1974).

Harris et al. (1955a, b) presented a classification of completely recessive and incompletely recessive cystinuria, representing about two-thirds and onethird of cases respectively. In the former group heterozygotes exhibit aminoaciduria. Incompletely recessive heterozygotes excreted increased amounts of amino acids, especially cystine and lysine. Rosenberg et al. (1966), from simultaneous studies of the intestinal transport defect, have more recently shown that there are at least three varieties of the disease. The only significant clinical manifestation of cystinuria is that of recurrent cystine stone formation. Both the mother and daughter in our family had homozygous cystinuria. The father excreted increased amounts of cystine and lysine and is presumably a heterozygote for the incompletely recessive form of cystinuria. The daughter had focal epilepsy from the age of 17 months. This is of interest as both Efron (1965) and Scriver et al. (1970) reported an increased incidence of cystinuria in mental disease and Cavanagh, Bicknell, and Howard (1974) reported delayed development, focal epileptic attacks, and paroxysmal dyskinesia in two brothers with cystinuria. They suggested that the slowly progressive neurological condition in these brothers was related to their biochemical abnormality.

The association between Lowe's syndrome and cystinuria in the family reported in this paper could be dismissed as being coincidental. However, this is most unlikely in view of the published evidence (Jagenburg, 1959; Terslev, 1960) of urinary amino acid excretion patterns similar to cystinuria in patients with Lowe's syndrome and particularly of Terslev's (1960) report of cystinuria in the mother of his patient. These findings make it likely that there is a connection between the defect in cystinuria and that of Lowe's syndrome.

We thank Dr. J. C. Marshall, Medical Superintendent, Templeton Hospital, for his help, and Mr. M. C. Owen for technical assistance. Miss Susan Small typed the manuscript.

\section{REFERENCES}

Abbassi, V., Lowe, C. U., and Calcagno, P. L. (1968). Oculocerebro-renal syndrome: a review. American fournal of Diseases of Children, 115, 145.

Bailey, R. R., Dann, E., Greenslade, N. F., Little, P. J., McRae, C. U., and Utley, W. L. F. (1974). Urinary stones: a prospective study of 350 patients. New Zealand Medical fournal, 79, 961.

Cavanagh, N. P. C., Bicknell, J., and Howard, F. (1974). Cystinuria with mental retardation and paroxysmal dyskinesia in two brothers. Archives of Disease in Childhood, 49, 662.

Cox, B. D., and Cameron, J. S. (1974). Homoarginine in cystinuria. Clinical Science and Molecular Medicine, 46, 173.

Crawhall, J. C., and Watts, R. W. E. (1968). Cystinuria. American fournal of Medicine, 45, 736.

Efron, M. L. (1965). Aminoaciduria. New England fournal of Medicine, 272, 1058.

Frimpter, G. W. (1961). The disulfide of L-cysteine and Lhomocysteine in urine of patients with cystinuria. Fournal of Biological Chemistry, 236, PC 51.

Harris, H., Mittwoch, U., Robson, E. B., and Warren, F. L. (1955a) The pattern of aminoacid excretion in cystinuria. Annals of Human Genetics, 19, 196.

Harris, H., Mittwoch, U., Robson, E. B., and Warren, F. L. (1955b). Phenotypes and genotypes in cystinuria. Annals of Human Genetics, 20, 57.

Jagenburg, O. R. (1959). The urinary excretion of free-aminoacids and other amino compounds by the human. Scandinavian fournal of Clinical and Laboratory Investigation, Suppl. 43.

Johnson, R. A., (1966). The oculo-cerebro-renal dystrophy of Lowe. New Zealand Medical fournal, 65, 243.

Lowe, C. U., Terrey, M., and MacLachlan, E. A. (1952). Organicaciduria, decreased renal ammonia production, hydrophthalmos and mental retardation: a clinical entity. American fournal of Diseases of Children, 83, 164.

Richards, W., Donnell, G. N., Wilson, W. A., Stowens, D., and Perry, T. (1965). The oculo-cerebral-renal syndrome of Lowe. American fournal of Diseases of Children, 109, 185.

Rosenberg, L. E., Downing, S., Durant, J. L., and Segal, S. (1966). Cystinuria: biochemical evidence for three genetically distinct diseases. Fournal of Clinical Investigation, 45, 365.

Schwartz, R., Hall, P. W., and Gabuzda, G. J. (1964). Metabolism of ornithine and other aminoacids in the cerebro-oculo-renal syndrome. American fournal of Medicine, 36, 778.

Scriver, C. R., Whelan, D. T., Clow, C. L., and Dallaire, L. (1970). Cystinuria: increased prevalence in patients with mental disease. New England fournal of Medicine, 283, 783.

Terslev, E. (1960). Two cases of aminoaciduria, ocular changes and retarded mental and somatic development (Lowe's syndrome). Acta Paediatrica, 49, 635.

Correspondence to Dr. Ross R. Bailey, Department of Renal Medicine, Christchurch Hospital, Christchurch 1, New Zealand. 